Article

\title{
An Optimization-Evaluation Agricultural Water Planning Approach Based on Interval Linear Fractional Bi-Level Programming and IAHP-TOPSIS
}

\author{
Yan Zhang ${ }^{1,2}$, Fan Zhang ${ }^{1,2}$, Hua Zhu ${ }^{3}$ and Ping Guo ${ }^{1,2, *}$ \\ 1 Centre for Agricultural Water Research in China, China Agricultural University, Beijing 10083, China; \\ zhangyand@163.com (Y.Z.); Zhagf@cau.edu.cn (F.Z.) \\ 2 Wuwei Experimental Station for Efficient Water Use in Agriculture, Ministry of Agriculture \\ and Rural Affairs, Wuwei 733000, China \\ 3 Faculty of Graduate Studies and Research, University of Regina, Regina, SK S4S 0A2, Canada; \\ zhu.marie@gmail.com \\ * Correspondence: guop@cau.edu.cn; Tel.: +86-10-6273-8496
}

Received: 5 April 2019; Accepted: 20 May 2019; Published: 24 May 2019

\begin{abstract}
In this study, an interval linear fractional bi-level programming (ILFBP) model was developed for managing irrigation-water resources under uncertainty. The ILFBP can fully address system fairness, uncertainties, and the leader-follower relationship of decision makers in the optimization process, which can better reflect the complexity of real decision-making process and help formulate reasonable water policies. An interactive fuzzy coordination algorithm based on satisfaction degree was introduced to solve the ILFBP model. In order to evaluate the applicability of optimization schemes, the interval analytic hierarchy process (IAHP) and the interval technique for order preference by similarity to an ideal solution (TOPSIS) method were integrated as IAHP-TOPSIS. To verify its validity, the developed optimization-evaluation framework was applied to an irrigation water management case study in the middle reaches of the Shiyang River Basin, located in the northwest China. The ILFBP model results show that the total water allocation is $[6.73,7.37] \times 10^{8} \mathrm{~m}^{3}$, saving nearly $0.9 \times 10^{8} \mathrm{~m}^{3}$ more than the current situation. The benefit per unit of water is $[2.38,2.95]$ yuan $/ \mathrm{m}^{3}$, nearly 0.4 yuan $/ \mathrm{m}^{3}$ more than the status quo, and the Gini coefficient is within a reasonable range of $[0.35,0.38]$. The ILFBP model can well balance economic benefits and system fairness. Through the evaluation bases on IAHP-TOPSIS, the results of ILFBP show better water allocation effects and applicability than the other two models in this study area. Furthermore, due to various characteristics such as geographical location, population and area, there are three irrigation districts, Xiying, Donghe, and Qinghe, showing higher importance than others when considering regional water allocation. These findings can provide useful information for limited water resource managers and help decision makers determine effective alternatives of water resource planning under uncertainty.
\end{abstract}

Keywords: bi-level programming; effect evaluation; interval analytic hierarchy process; interval TOPSIS method; uncertainty

\section{Introduction}

Water is an indispensable and essential resource for human survival and development. With the development of social economy, the conflicts between supplies and demands of water resources have become increasingly prominent [1]. As the large freshwater consumer, agriculture accounts for more than $70 \%$ of the total freshwater consumption in the world [2,3]. Especially in the semi-arid and arid regions, water deficits limit sustainable development of the local agriculture, and thus more efforts should be made to improve the usage efficiency of limited irrigation water [4]. 
The agricultural water management systems are complicated with multiple uncertainties, including inexactness, fuzziness, and randomness existed in precipitation and river runoff, crop market prices variations, and irrigation target adjustments. The necessity of dealing with these uncertainties brings a lot of difficulties in the planning processes of irrigation water management $[5,6]$. To address these uncertainties in practical problems, many methods have been proposed for helping decision makers formulate better water policies [7-11]. Generally, these methods can be categorized into fuzzy programming (FP), stochastic programming (SP), and interval programming (IP). Among these categories, IP is the most widely used planning method under uncertainty due to its low data requirements $[12,13]$. Although IP can deal with the uncertainties expressed as interval numbers, it cannot fully reflect multiple decision-making hierarchy in the practical problems. To obtain the satisfied irrigation water allocation schemes, the various requirements from decision makers of different levels should be taken into account within one framework when formulating allocation models [14]. To reflect the tradeoff between two decision-making levels with different concerns, the bi-level programing (BP) approach with a two-level structure was developed for supporting regional water policies formulation [15]. A leader-follower decision-making strategy was incorporated into the optimization process of BP to generate satisfied decision-making plan for both the upper-level and the lower-level decision makers. However, more challenges exist when attempting to tackle interval uncertainty and coordinate the preferences of different-level stakeholders simultaneously.

In recent years, some researches were conducted to integrate interval linear programming (ILP) and BP into one framework to address such problems in irrigation water management [16]. An interval linear bi-level programming (ILBP) approach was thus developed and applied to real-world problems of water resources planning to address different-level decision-making preferences and uncertainties expressed as intervals [17]. These researches proved that ILBP would be an effective tool for decision makers to formulate water policies. However, the concerns of decision makers in these researches mainly focused on the economic and environmental factors such as benefits and water volumes water resource allocation systems. It was neglected that water resources are not only accounted as economic resources but also represent a kind of social resource. Unfair allocations among water users sometimes may lead to serious social conflicts. Therefore, the fairness issue needs to be considered in the water resource allocation process [18,19]. Many indicators have been proposed for measuring system fairness, such as the Gini coefficient, weighted proportional fairness, and so on [20-22]. Among them, the Gini coefficient is the most widely used measurement of inequality [23,24]. The Gini coefficient was proposed by the Italian economist Corrado Gini in 1912 to measure the balance of income in a country or region. It is usually calculated via the Lorenz curve [25], and has been applied to the fairness studies in many fields of education, economy, and resources management [22,26-28]. Therefore, the Gini coefficient is considered as a proper configuration goal of water resources planning to guarantee the fairness of water allocation. However, because the Gini coefficient is always presented as fractional, it is necessary to introduce the interval linear fractional programming (ILFP) model into the ILBP framework to solve such a problem. This results in the development of an interval linear fractional bi-level programming (ILFBP) model, which can simultaneously tackle interval uncertainty, coordinate the preferences of different-level decision makers and reflect system fairness in one framework to obtain satisfied water allocation schemes.

Moreover, although the mathematical optimization models can generate water allocation schemes under uncertainty, few of them are incorporated with the results evaluation methods to measure their applicability and effectiveness in specific cases. This limitation may reduce the guiding significance of these optimization planning results in real-world practice [29-31]. Therefore, the evaluation methods based on actual regional conditions are necessary for measuring impacts of implementing the optimization results in various agricultural regions [32]. However, compared to general evaluation methods proposed for assessing the deterministic optimization results, the evaluation of optimization results under interval uncertainty would be more difficult. In order to address such a challenge, an interval analytic hierarchy process (IAHP) method has been proposed to address system 
uncertainties associated with systematic errors, incomplete information and fuzzy subjective judgment, and shown good performance in evaluating multiple schemes under interval uncertainty [33,34]. Generally, the calculation of IAHP often involves the ordering of interval numbers and the typical method is to directly use the mean of the interval numbers (i.e., the average of the upper and lower bounds) [35]. The limitation of this approach is that it ignores the effects of interval lengths and might lead to unreasonable comparison results. Besides, the possibility matrix has been used in many researches as a possible way to sort interval numbers [36,37], but it becomes complicated and inefficient when dealing with more than two indicators. More effective methods are thus needed to sort interval numbers in the results evaluation process. As the interval-parameter TOPSIS (ITOPSIS) could sort interval numbers via calculating the distances of alternative schemes to the ideal scheme, the integrated method of IAHP and ITOPSIS (IAHP-TOPSIS) is considered as an effective way to deal with interval numbers' sorting in the evaluation of optimization results [38-40]. Through the IAHP-TOPSIS method, the effects evaluation of the optimization schemes can be carried out and would further provide decision-making support for local water policies development. There have been few studies that can address both optimization and evaluation processes within one framework and simultaneously consider interval characteristics associated with agriculture water management systems.

The main objective of this study is to develop an optimization-evaluation approach for agricultural water planning based on the ILFBP and IAHP-TOPSIS methods to help decision makers formulate reasonable regional water policies. The optimization model (ILFBP) proposed for optimal irrigation water allocation and the evaluation model (IAHP-TOPSIS) used for evaluating the effectiveness of optimization schemes will be integrated within one framework under interval uncertainty to address the complexities of practical problems. Such an approach can: (1) Tackle interval numbers existed in both optimization and evaluation processes; (2) consider the fairness issue in water allocation; (3) make trade-offs between different concerns of two-level decision makers; (4) generate multiple water resource allocation schemes under different runoff levels; and (5) provide the corresponding evaluation results of the obtained allocation schemes. The proposed approach will also be applied to a real-world case study to demonstrate its applicability and effectiveness, wherein the regional water managers need to identify more effective irrigation water allocation policies to support the sustainable development of local agriculture.

\section{Methodology}

This section presents the development of an optimization-evaluation framework for an agricultural water allocation system, which entails the following three major components: (1) The parameter preprocessing and development of interval linear fractional bi-level programming (ILFBP); (2) the ILFBP model for irrigation water resources optimal allocation; and (3) the IAHP-TOPSIS method for evaluating the effectiveness of the optimization schemes. These components and their connections are shown in Figure 1 in detail. 


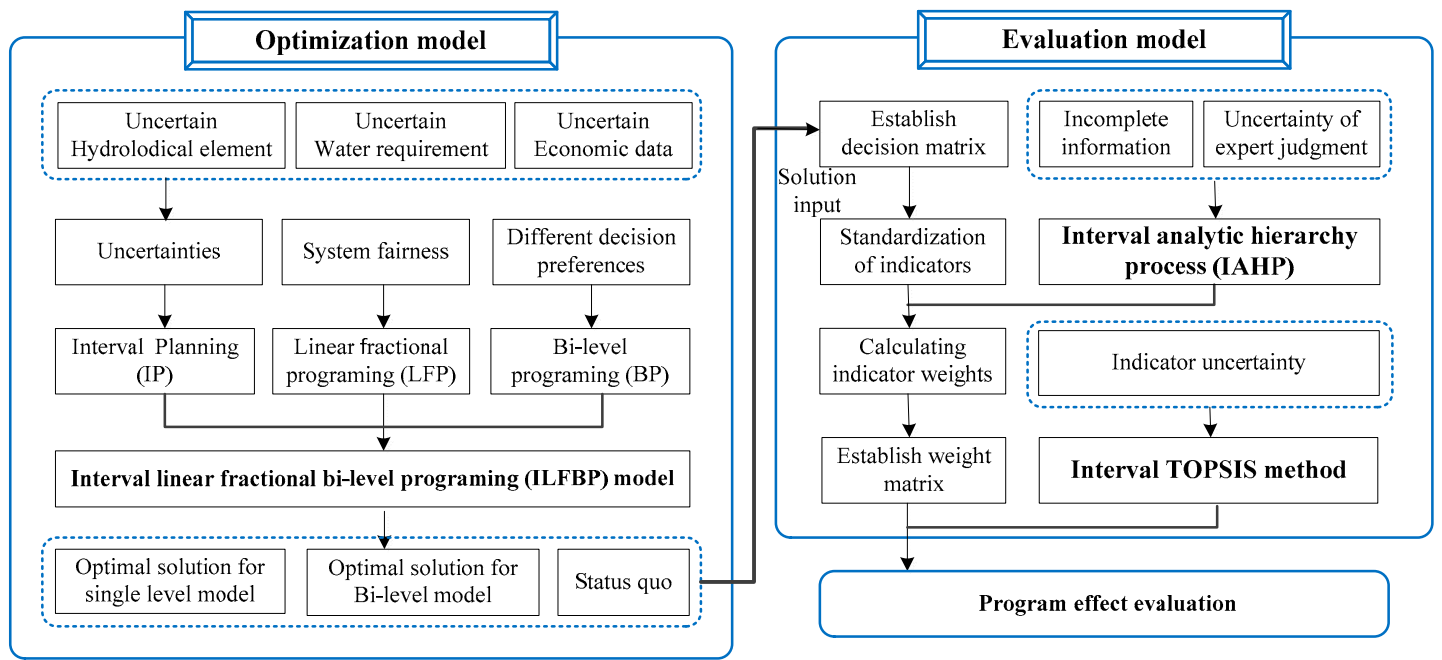

Figure 1. Model framework.

\subsection{Interval Linear Fractional Bi-Level Programming (ILFBP)}

The general ILFBP problem can be described follows [41,42]:

(Upper-level objective)

$$
\min f_{1}^{ \pm}\left(x_{1}^{ \pm}, x_{2}^{ \pm}\right)=\frac{c_{11}^{ \pm} x_{1}^{ \pm}+c_{12}^{ \pm} x_{2}^{ \pm}+\alpha_{1}^{ \pm}}{d_{11}^{ \pm} x_{1}^{ \pm}+d_{12}^{ \pm} x_{2}^{ \pm}+\beta_{1}^{ \pm}}
$$

(Lower-level objective)

$$
\min f_{2}^{ \pm}\left(x_{1}^{ \pm}, x_{2}^{ \pm}\right)=\frac{c_{21}^{ \pm} x_{1}^{ \pm}+c_{22}^{ \pm} x_{2}^{ \pm}+\alpha_{2}^{ \pm}}{d_{21}^{ \pm} x_{1}^{ \pm}+d_{22}^{ \pm} x_{2}^{ \pm}+\beta_{2}^{ \pm}}
$$

Subject to:

$$
G^{ \pm}=\left\{\left(x_{1}^{ \pm}, x_{2}^{ \pm}\right) \mid g_{\dot{i}}^{ \pm}\left(x_{1}^{ \pm}, x_{2}^{ \pm}\right) \leq 0, \quad i=1,2, \cdots, m, x_{1}^{ \pm}, x_{2}^{ \pm} \geq 0\right\}
$$

where the upper-level variables are $x_{1} \in R^{n 1}$ and the lower-level variables are $x_{2} \in R^{n 2}$; $c_{11}, c_{21}, c_{12}, c_{22}, d_{11}, d_{21}, d_{12}, d_{22}, \alpha_{1}, \beta_{1}, \alpha_{2}, \beta_{2}$ are interval parameters; $G$ is the set of bi-level constraints; $f_{1}$ and $f_{2}$ are the upper-level and lower-level objective functions, respectively; the upper-level decision maker (ULDM) and the lower-level decision maker (LLDM) accept the leader-follower Stackelberg game [43].

To solve model (1), an interactive fuzzy coordination algorithm is proposed through analyzing the interrelationship between the objective functions and the constraints $[16,41]$. The upperand lower-bound submodels of the ILFBP can be decomposed [44]. In particular, when the number of interval parameters in the ILFBP model is relatively small, the upper- or lower-bound parameters corresponding to two ILFBP submodels can be determined respectively by comparing all the combinations of the intervals. If the objective functions of the ULDM and LLDM problems are formulated as the maximization goals, they need to be converted as the equivalent minimization goals, i.e., $\max f=\min (-f)$, and then the general ILFBP model can be solved according to following steps.

(1) The ILFBP submodel corresponding to the lower-bound objectives can be formulated as:

$$
\begin{aligned}
& \min f_{1}^{-}\left(x_{1}^{-}, x_{2}^{-}\right) \\
& \min f_{2}^{-}\left(x_{1}^{-}, x_{2}^{-}\right)
\end{aligned}
$$


Subject to:

$$
G^{-}=\left\{\left(x_{1}^{-}, x_{2}^{-}\right) \mid g_{\mathrm{i}}^{-}\left(x_{1}^{-}, x_{2}^{-}\right) \leq 0, \quad i=1,2, \cdots, m, \quad x_{1}^{-}, x_{2}^{-} \geq 0\right\}
$$

(2) The ULDM problem and the LLDM problem can be solved independently with the solutions of $\left(x_{1}^{U-}, x_{2}^{U-}, f_{1}^{U-}\right)$ and $\left(x_{1}^{L-}, x_{2}^{L-}, f_{1}^{L-}\right)$. The ranges of the decision variables $\left(x_{1}^{-}\right)$should be around within the maximum tolerances $\left(r_{1}^{-}\right)$of their most preferred values. The membership functions that specify the satisfaction degrees of $x_{1}^{-}$can be presented as follows:

$$
\mu_{x_{1}^{-}}\left(x_{1}^{-}\right)=\left\{\begin{array}{cc}
\frac{x_{1}^{-}-\left(x_{1}^{U-}-r_{1}^{-}\right)}{r_{1}^{-}}, & x_{1}^{U-}-r_{1}^{-}<x_{1}^{-}<x_{1}^{U-} \\
\frac{\left(x_{1}^{U-}+r_{1}^{-}\right)-x_{1}^{-}}{r_{1}^{-}}, & x_{1}^{U-}<x_{1}^{-}<x_{1}^{U-}+r_{1}^{-} \\
0, & \text { otherwise }
\end{array}\right.
$$

where $x_{1}^{U-}$ are the most preferred values of upper-level decision variables while $\left(x_{1}^{U-}+r_{1}^{-}\right)$ and $\left(x_{1}^{U-}-r_{1}^{-}\right)$are the least preferred values of upper-level decision variables; $\mu_{x_{1}^{-}}\left(x_{1}^{-}\right)$are the satisfaction degrees of the upper-level decision variables $x_{1}^{-}$, which increase within the intervals of $\left[x_{1}^{U-}-r_{1}^{-}, x_{1}^{U-}\right]$ and decrease within the intervals of $\left[x_{1}^{U-}, x_{1}^{U-}+r_{1}^{-}\right]$, even though the other decision variable values are not acceptable.

(3) For the ULDM problem, the objective function can be considered acceptable when $f_{1}^{-} \leq f_{1}^{U-}$ and unacceptable when $f_{1}^{-} \geq f_{1}^{\prime-}=f_{1}^{-}\left(x_{1}^{L-}, x_{2}^{L-}\right)$. The LLDM problem can be solved with the optimal solutions of $\left(x_{1}^{L-}, x_{2}^{L-}\right)$, which in turn provides the ULDM problem with the objective value of $f_{1}^{\prime-}$ by considering $f_{1}^{-} \geq f_{1}^{\prime-}$ unacceptable in practice. The membership function that specifies the satisfaction degree of the ULDM objective value can be stated as:

$$
\mu_{f_{1}^{-}}\left[f_{1}^{-}(x)\right]=\left\{\begin{array}{cc}
1, & f_{1}^{-}(x)<f_{1}^{U-} \\
\frac{f_{1}^{\prime-}-f_{1}^{-}(x)}{f_{1}^{\prime-}-f_{1}^{U-},} & f_{1}^{U-}<f_{1}^{-}(x)<f_{1}^{\prime-} \\
0, & f_{1}^{-}(x)>f_{1}^{\prime-}
\end{array}\right.
$$

In contrast, the LLDM objective value has the following membership function:

$$
\mu_{f_{2}^{-}}\left[f_{2}^{-}(x)\right]=\left\{\begin{array}{cc}
1, & f_{2}^{-}(x)<f_{2}^{L-} \\
\frac{f_{2}^{\prime-}-f_{2}^{-}(x)}{f_{2}^{\prime-}-f_{2}^{L-}}, & f_{2}^{L-}<f_{2}^{-}(x)<f_{2}^{\prime-} \\
0, & f_{2}^{-}(x)>f_{2}^{\prime-}
\end{array}\right.
$$

where $f_{2}^{\prime-}=f_{2}^{-}\left(x_{1}^{U-}, x_{1}^{U-}\right)$ and the preference decreases within the interval of $\left[f_{2}^{L-}, f_{2}^{\prime-}\right]$.

(4) Consequently, the solution of submodel (2) with maximum overall satisfaction for both the ULDM and LLDM can be obtained through the following model:

$$
\max \lambda^{-}
$$

Subject to:

$$
\begin{gathered}
x^{-} \in G^{-} \\
\mu_{x_{1}^{-}}\left(x_{1}^{-}\right) \geq \lambda^{-} I \\
\mu_{f_{1}^{-}}\left[f_{1}^{-}(x)\right] \geq \lambda^{-} \\
\mu_{f_{2}^{-}}\left[f_{2}^{-}(x)\right] \geq \lambda^{-}
\end{gathered}
$$




$$
\begin{aligned}
& x_{1}^{-}, x_{2}^{-} \geq 0 \\
& \lambda^{-} \in[0,1]
\end{aligned}
$$

where $\lambda^{-}$is the overall satisfactory degree of the lower-bound ILFBP submodel; $I$ is a column vector with the same dimension as $\mu_{x_{1}^{-}}$or $x_{1}^{-}$and all elements of $I$ are equal to 1 . Thus, the solutions of the lower-bound ILFBP submodel and the corresponding objective values (i.e., $x_{1 \text { opt }}^{-} x_{2 o p t}^{-}, f_{10 p t}^{-}$and $f_{2 o p t}^{-}$) can be obtained through model (6).

(5) Accordingly, the upper-bound ILFBP submodel can be formulated as follows: (Upper-level objective)

$$
\min f_{1}^{+}\left(x_{1}^{+}, x_{2}^{+}\right)
$$

(Lower-level objective)

$$
\min f_{2}^{+}\left(x_{1}^{+}, x_{2}^{+}\right)
$$

Subject to:

$$
\begin{aligned}
G^{+}=\left\{\left(x_{1}^{+}, x_{2}^{+}\right) \mid g_{\mathrm{i}}^{+}\left(x_{1}^{+}, x_{2}^{+}\right) \leq\right. & \left.0, \quad i=1,2, \cdots, m, \quad x_{1}^{+}, x_{2}^{+} \geq 0\right\} \\
& x_{1}^{+} \geq x_{1 \mathrm{opt}}^{-} \\
& x_{2}^{+} \geq x_{2 \mathrm{opt}}^{-}
\end{aligned}
$$

(6) Similar to the solution process of submodel (2), the solution of submodel (7) with maximum overall satisfaction for both the ULDM and LLDM can be obtained through the following model:

$$
\max \lambda^{+}
$$

Subject to:

$$
\begin{gathered}
x^{+} \in G^{+} \\
\mu_{x_{1}^{+}}\left(x_{1}^{+}\right) \geq \lambda^{+} I \\
\mu_{f_{1}^{+}}\left[f_{1}^{+}(x)\right] \geq \lambda^{+} \\
\mu_{f_{2}^{+}}\left[f_{2}^{+}(x)\right] \geq \lambda^{+} \\
x_{1}^{+} \geq x_{1 \mathrm{opt}}^{-} \\
x_{2}^{+} \geq x_{2 \mathrm{opt}}^{-} \\
\lambda^{+} \in[0,1]
\end{gathered}
$$

where:

$$
\begin{gathered}
\mu_{x_{1}^{+}}\left(x_{1}^{+}\right)=\left\{\begin{array}{cc}
\frac{x_{1}^{+}-\left(x_{1}^{U+}-r^{+}\right)}{r_{1}^{+}}, & x_{1}^{U+}-r_{1}^{+}<x_{1}^{+}<x_{1}^{U+} \\
\frac{\left(x_{1}^{U+}+r_{1}^{+}\right)-x_{1}^{+}}{r_{1}^{-}}, & x_{1}^{U+}<x_{1}^{+}<x_{1}^{U+}+r_{1}^{+} \\
0, & \text { otherwise }
\end{array}\right. \\
\mu_{f_{1}^{+}}\left[f_{1}^{+}(x)\right]=\left\{\begin{array}{cc}
1, & f_{1}^{+}(x)<f_{1}^{U+} \\
\frac{f_{1}^{\prime+}-f_{1}^{+}(x)}{f_{1}^{\prime+}-f_{1}^{U+}}, & f_{1}^{U+}<f_{1}^{+}(x)<f_{1}^{\prime+} \\
0, & f_{1}^{+}(x)>f_{1}^{\prime+}
\end{array}\right.
\end{gathered}
$$




$$
\mu_{f_{2}^{+}}\left[f_{2}^{+}(x)\right]=\left\{\begin{array}{cc}
1, & f_{2}^{+}(x)<f_{2}^{L+} \\
\frac{f_{2}^{\prime+}-f_{2}^{+}(x)}{f_{2}^{\prime \prime}-f_{2}^{L+}}, & f_{2}^{L+}<f_{2}^{+}(x)<f_{2}^{\prime+} \\
0, & f_{2}^{+}(x)>f_{2}^{\prime+}
\end{array}\right.
$$

The solutions of the upper-bound ILFBP submodel and the objective values (i.e., $x_{1 o p t^{\prime}}^{+} x_{2 o p t^{\prime}}^{+} f_{1 o p t^{\prime}}^{+}$and $f_{2 o p t}^{+}$) can be obtained from model (8).

(7) Finally, the solutions for the ILFBP model can be generated as follows:

$$
\begin{aligned}
& x_{1 o p t}^{ \pm}=\left[x_{1 o p t}^{-}, x_{1 o p t}^{+}\right] \\
& x_{2 o p t}^{ \pm}=\left[x_{2 o p t}^{-}, x_{2 o p t}^{+}\right] \\
& f_{1 o p t}^{ \pm}=\left[f_{1 o p t}^{-}, f_{1 o p t}^{+}\right] \\
& f_{2 o p t}^{ \pm}=\left[f_{2 o p t}^{-}, f_{2 o p t}^{+}\right]
\end{aligned}
$$

\subsection{The ILFBP Model for Agricultural Water Resources Management}

To achieve effective management of limited irrigation water resources, the decision makers often desire optimal allocation schemes to avoid high costs and large water consumptions, especially for the arid and semi-arid areas. Moreover, the decision makers need to consider the system fairness, balance the different-level preferences, and address interval uncertainties in practical problems [45-47]. To deal with these challenges of agricultural water resources management, an ILFBP model can be formulated as follows:

(Upper-level objective)

$$
\max f_{1}^{ \pm}=\sum_{i=1}^{I} \sum_{j=1}^{J} \sum_{h=1}^{H} p_{h}\left(B_{i j}^{ \pm} \cdot Y_{i j}^{ \pm} \cdot\left(W_{i j h}^{ \pm} \cdot k_{i}+P_{i j h}^{ \pm}\right)-J L_{i} \cdot W_{i j h}^{ \pm}\right)-\sum_{i=1}^{I} J B_{i} \cdot A_{i}
$$

where $f_{1}$ is the upper-level objective of maximizing the system's net economic benefits (yuan); $i$ is the index for irrigation districts $(i=1,2, \ldots, 10) ; j$ denotes the type of crops $(j=1,2,3) ; h$ denotes the levels of water availability $(h=1,2,3,4,5) ; W_{i j h}$ are the decision variables, representing the amount of irrigation water allocated to the crop $j$ in the irrigation district $i$ under the flow level $h\left(\mathrm{~m}^{3}\right) ; p_{h}$ are the possibilities of different water levels; $B_{i j}$ are the prices of crop $j$ in the irrigation district $i$ (yuan $/ \mathrm{kg}$ ); $Y_{i j}$ are water productivities of crop $j$ in the irrigation district $i\left(\mathrm{~kg} / \mathrm{m}^{3}\right) ; A_{i}$ are irrigated areas of subarea $i$ (ha); $k_{i}$ are the irrigation water use efficiencies; $P_{i j h}$ are effective precipitations $\left(\mathrm{m}^{3}\right) ; J B_{i}$ are basic water prices (yuan/ha); and $J L_{i}$ are the metering water prices (yuan $/ \mathrm{m}^{3}$ ).

(Lower-level objective)

$$
\min f_{2}^{ \pm}=\frac{\sum_{l=1}^{I} \sum_{k=1}^{I}\left|\frac{\sum_{j=1}^{I} \sum_{h=1}^{H} p_{h}\left(W_{i j h}^{ \pm}+P_{i j h}^{ \pm}\right)}{R_{l}}-\frac{\sum_{j=1}^{I} \sum_{h=1}^{H} p_{h}\left(W_{k j h}^{ \pm}+P_{k j h}^{ \pm}\right)}{R_{k}}\right|}{2 I \sum_{i=1}^{I} \sum_{j=1}^{J} \sum_{h=1}^{H} \frac{p_{h}\left(W_{i j h}^{ \pm}+P_{i j h}^{ \pm}\right)}{R_{i}}}
$$

where $f_{2}$ is the lower-level objective function to reflect the fairness of water allocation among irrigation districts via the Gini coefficient; and $R_{i}$ are populations of the irrigation district $i$.

The Gini coefficient varies within the range of $[0,1]$. The smaller Gini coefficient represents the higher fairness of water allocation among irrigation districts. Conversely, the larger Gini coefficient 
represents the lower fairness of water allocation. In regard to income distribution levels, a Gini coefficient less than 0.2 stands for absolute evenness, that between 0.2 and 0.3 represents relative evenness, that between 0.3 and 0.4 indicates basically reasonable distribution, and that between 0.4 and 0.5 indicates unreasonable distribution. When a Gini coefficient reaches 0.5 or more, it means a significant gap in income levels. Generally, a Gini coefficient higher than 0.4 is used as a sign of unfairness.

Subject to:

(1) Water availability constraint

$$
\begin{gathered}
\sum_{i=1}^{I} \sum_{j=1}^{J} W_{i j h}^{ \pm} \leq T W_{h}^{ \pm} \quad \forall h \\
\sum_{j=1}^{J} W_{i j h}^{ \pm} \leq T W_{i h}^{ \pm} \forall i, h
\end{gathered}
$$

where $T W_{h}$ are the total water supplies $\left(\mathrm{m}^{3}\right)$ under the flow level $h$; and $T W_{i h}$ denote the water supplies $\left(\mathrm{m}^{3}\right)$ for the irrigation district $i$ under flow level $h$.

(2) Irrigation water demand constraint

$$
I R_{i j h \text {, min }}^{ \pm} \leq W_{i j h}^{ \pm} \cdot k_{i}+P_{i j h}^{ \pm} \leq I R_{i j h \text {,max }}^{ \pm} \forall i, j, h
$$

where $I R_{i j h \text {, min }}^{ \pm}$and $I R_{i j h \text {, max }}^{ \pm}$are respectively the minimum and maximum crop water requirement $\left(\mathrm{m}^{3}\right)$ of crop $j$ in the irrigation district $i$ under flow level $h$.

(3) Non-negative constraint

$$
W_{i j h}^{ \pm} \geq 0 \quad \forall i, j, h
$$

\subsection{The IAHP-TOPSIS Evaluation Approach Coupling the IAHP and ITOPSIS Methods}

The IAHP method is widely used for multi-criteria decision making (MCDM) under uncertainty [48]. It can build an evaluation framework based on the analysis of interval parameters, and obtain the interval weights of the indicators. However, more effective methods are needed to sort interval numbers when using the IAHP. The interval-parameter TOPSIS method (ITOPSIS) can analyze the uncertain information of the scheme results and sort interval numbers through measuring the distances between solution alternatives and the ideal solution. Therefore, for improving the assessment accuracy under interval uncertainty, the IAHP and ITOPSIS methods are integrated to evaluate the optimal allocation results of water resources. Particularly, the IAHP method is used for calculating the indicators' interval weights and the ITOPSIS method is used for ranking the uncertain water resources allocation schemes. The specific steps can be shown as follows [33,40,49]:

(1) Suppose a MCDM problem with $m$ alternatives $X_{m}(m=1,2, \cdots, M)$, and $n$ criteria $Y_{n}(n=1,2, \cdots, N)$. All indicators in MCDM are interval numbers, and thus an interval-number decision matrix $A^{ \pm}=\left(a_{m n}^{ \pm}\right)_{M \times N}$ can be established.

(2) Normalize the decision matrix to obtain a standardized interval-number decision matrix $R^{ \pm}=\left(r_{m n}^{ \pm}\right)_{M \times N}$ as follows:

$$
\left[r_{m n}^{-}, r_{m n}^{+}\right]=\frac{\left[a_{m n}^{-}, a_{m n}^{+}\right]}{\left\|A_{n}\right\|}, m=1,2, \cdots, M, \quad n=1,2, \cdots, N
$$

where $\left\|A_{n}\right\|$ is the norm of the $n$th column vector and we have: $\left\|A_{n}\right\|=\max \left(\max \left(\left|a_{1 n}^{-}\right|,\left|a_{1 n}^{+}\right|\right), \max \left(\left|a_{2 n}^{-}\right|,\left|a_{2 n}^{+}\right|\right), \cdots, \max \left(\left|a_{M n}^{-}\right|,\left|a_{M n}^{+}\right|\right)\right), \quad n=1,2, \cdots, N$. Please note the reverse indicators need to be converted to positive indicators as: $\left[c_{m n}^{-}, c_{m n}^{+}\right]=\left[-a_{m n}^{+},-a_{m n}^{-}\right]$. Therefore, all the metrics are positive metrics. 
(3) Invite experts to compare the importance of indicators. According to the experts' opinions, a judgment matrix can be built as follows with the interval numbers [31]:

$$
B=\left[\begin{array}{cccc}
{[1,1]} & {\left[b_{12}^{-}, b_{12}^{+}\right]} & \cdots & {\left[b_{1 N}^{-}, b_{1 N}^{+}\right]} \\
{\left[\frac{1}{b_{12}^{+}}, \frac{1}{b_{12}^{-}}\right]} & {[1,1]} & \cdots & {\left[b_{2 N}^{-}, b_{2 N}^{+}\right]} \\
\vdots & \vdots & & \vdots \\
{\left[\frac{1}{b_{1 N}^{+}}, \frac{1}{b_{1 N}^{-}}\right]} & {\left[\frac{1}{b_{2 N}^{+}}, \frac{1}{b_{2 N}^{-}}\right]} & \cdots & \vdots 1,1]
\end{array}\right]
$$

where $b_{m n}=\left[b_{m n}^{-}, b_{m n}^{+}\right], 1 \leq b_{m n}^{-} \leq b_{m n}^{+} \leq 9, B^{ \pm}=\left(b_{m n}^{ \pm}\right)_{N \times N}$.

(4) Calculate the eigenvectors $x_{n}^{-}, x_{n}^{+}$, which corresponding to the largest eigenvalues of the judgment matrices $B^{-}$and $B^{+}$, respectively. Then calculate the interval weights using the interval number eigenvalue method as follows [50].

$$
w_{n}^{ \pm}=\left[k x_{n}^{-}, l x_{n}^{+}\right]
$$

where $k=\sqrt{\sum_{n=1}^{N} \frac{1}{\sum_{m=1}^{N} b_{m n}^{+}}}, l=\sqrt{\sum_{n=1}^{N} \frac{1}{\sum_{m=1}^{N} b_{m n}^{-}}}$.

(5) Judgment matrix consistency test. If $0 \leq k \leq 1 \leq l$, the consistency of the interval judgment matrix $B$ is reasonable [36]. If $k>1$ or $l<1$, the consistency of the judgment matrix is poor. The results should be sent back to the experts, and the judgment matrix should be corrected or re-judged until the consistency requirements are met.

(6) Multiply the columns of normalized decision matrix by the associated weights:

$$
S^{ \pm}=\left(s_{m n}^{ \pm}\right)_{M \times N^{\prime}}\left[s_{m n}^{-}, s_{m n}^{+}\right]=\left[w_{n}^{-}, w_{n}^{+}\right] \times\left[r_{m n}^{-}, r_{m n}^{+}\right], m=1,2, \cdots, M, n=1,2, \cdots, N
$$

It can be calculated based on the calculation principle of interval number multiplication [49].

(7) Respectively determine the positive ideal and negative ideal solutions:

$$
\begin{aligned}
& t_{n}^{-}=\max _{1 \leq m \leq M} s_{m n}^{-}, t_{n}^{+}=\max _{1 \leq m \leq M} s_{m n}^{+} \\
& p_{n}^{-}=\min _{1 \leq m \leq M} s_{m n}^{-}, p_{n}^{+}=\min _{1 \leq m \leq M} s_{m n}^{+}
\end{aligned}
$$

The positive ideal solution is $X^{+}=\left(\left[t_{1}^{-}, t_{1}^{+}\right],\left[t_{2}^{-}, t_{2}^{+}\right], \cdots,\left[t_{N^{\prime}}^{-}, t_{N}^{+}\right]\right)$; the negative ideal solution is $X^{-}=\left(\left[p_{1}^{-}, p_{1}^{+}\right],\left[p_{2}^{-}, p_{2}^{+}\right], \cdots,\left[p_{N^{\prime}}^{-} p_{N}^{+}\right]\right)$.

(8) Calculate the distances between each solution alternative and the ideal solution.

(9) The distance from the scheme alternative $X_{m}$ to the positive ideal solution is:

$$
d_{m}^{+}=d\left(X_{m}, X^{+}\right)=\sqrt{\sum_{n=1}^{N}\left(d_{m n}^{+}\right)^{2}}
$$

where $d_{m n}^{+}=\max \left(\left|s_{m n}^{-}-t_{m n}^{-}\right|,\left|s_{m n}^{+}-t_{m n}^{+}\right|\right)$. The distance from the scheme alternative $X_{m}$ to the negative ideal solution is:

$$
d_{m}^{-}=d\left(X_{m}, X^{-}\right)=\sqrt{\sum_{n=1}^{N}\left(d_{m n}^{-}\right)^{2}}
$$


where $d_{m n}^{-}=\max \left(\left|s_{m n}^{-}-p_{m n}^{-}\right|,\left|s_{m n}^{+}-p_{m n}^{+}\right|\right)$.

(10) Calculate the proximity of each scenario to a positive ideal.

$$
C_{m}=\frac{d_{m}^{-}}{d_{m}^{-}+d_{m}^{+}}
$$

(11) Rank the alternatives according to the relative closeness to the ideal alternatives, the larger value of $C_{m}$ means better effects of the corresponding scheme.

\section{Case Study}

\subsection{Study Area}

Shiyang River Basin $\left(101^{\circ} 41^{\prime}-104^{\circ} 16^{\prime}\right.$ E, $\left.36^{\circ} 29^{\prime}-39^{\circ} 27^{\prime} \mathrm{N}\right)$, as shown in Figure 2, is one of three inland rivers in the Hexi Corridor of Gansu Province in northwest China. The Shiyang River Basin has a typical arid continental climate, which is featured by low and irregular rainfalls, high evaporation rates, and long drought periods [51-53]. Since the 1960s, the population of the Shiyang River Basin has increased significantly, the scale of agricultural production has expanded, and the underground water resources in the basin have been overexploited. These changes caused the deterioration of the ecological environment and water shortage problems. In order to restore the ecological environment of the Shiyang River Basin, the local government formulated a series of policies such as the "Shiyang River Basin Key Management Plan" [54] and a series of supportive policies. However, in recent years, due to the decreased river runoff, the water shortage problems in the middle reaches of the Shiyang River Basin are becoming more and more serious. Irrigation is the largest water consumer in the middle reaches of the Shiyang River Basin, accounting for $88.28 \%$ of the total water consumptions [29]. The low efficiency of irrigation water usage further deepens the gap between water demands and supplies. Therefore, the practical allocation methods of irrigation water resources are highly desired to improve water usage efficiency in the middle reaches of the Shiyang River Basin.

The study area was a mountain plain located in the middle reaches of the Shiyang River Basin, which is called the Wuwei Basin. It includes two districts: The Liangzhou District of Wuwei City and the Yongchang County of Jinchang City. The dominated industry of the Wuwei Basin is agriculture and the local economy is relatively undeveloped. There are six rivers in the Wuwei Basin, namely the Dongda River, the Xiying River, the Jinta River, the Zamu River, the Huangyang River, and the Gulang River. These rivers can provide agricultural irrigation water for six irrigation districts located in the south of the study area, including Gulang (GL), Huangyang (HY), Zamu (ZM), Jinta (JT), Xiying $(\mathrm{XY})$, and Donghe (DH). In addition, there are four groundwater irrigation districts in the north of the study area, including Qingyuan (QY), Jingyang (JY), Yongchang (YC), and Qinghe $(\mathrm{QH})$ [55]. The surface water flows and groundwater withdrawals can be represented as stochastic distributions. Aiming to allocate the limited irrigation water resources in the Wuwei Basin, the decision makers from different hierarchical levels are responsible for making decision preferences from different viewpoints. The upper-level decision makers always rank the economy development as the primary goal, while the lower-level decision makers always focus on the fairness of water allocation among the irrigation districts to avoid social conflicts. Therefore, a comprehensive planning approach based on the ILFBP model and the IAHP-TOPSIS method would be applied to the study area to help water managers formulate well-rounded water allocation schemes under uncertainty. 


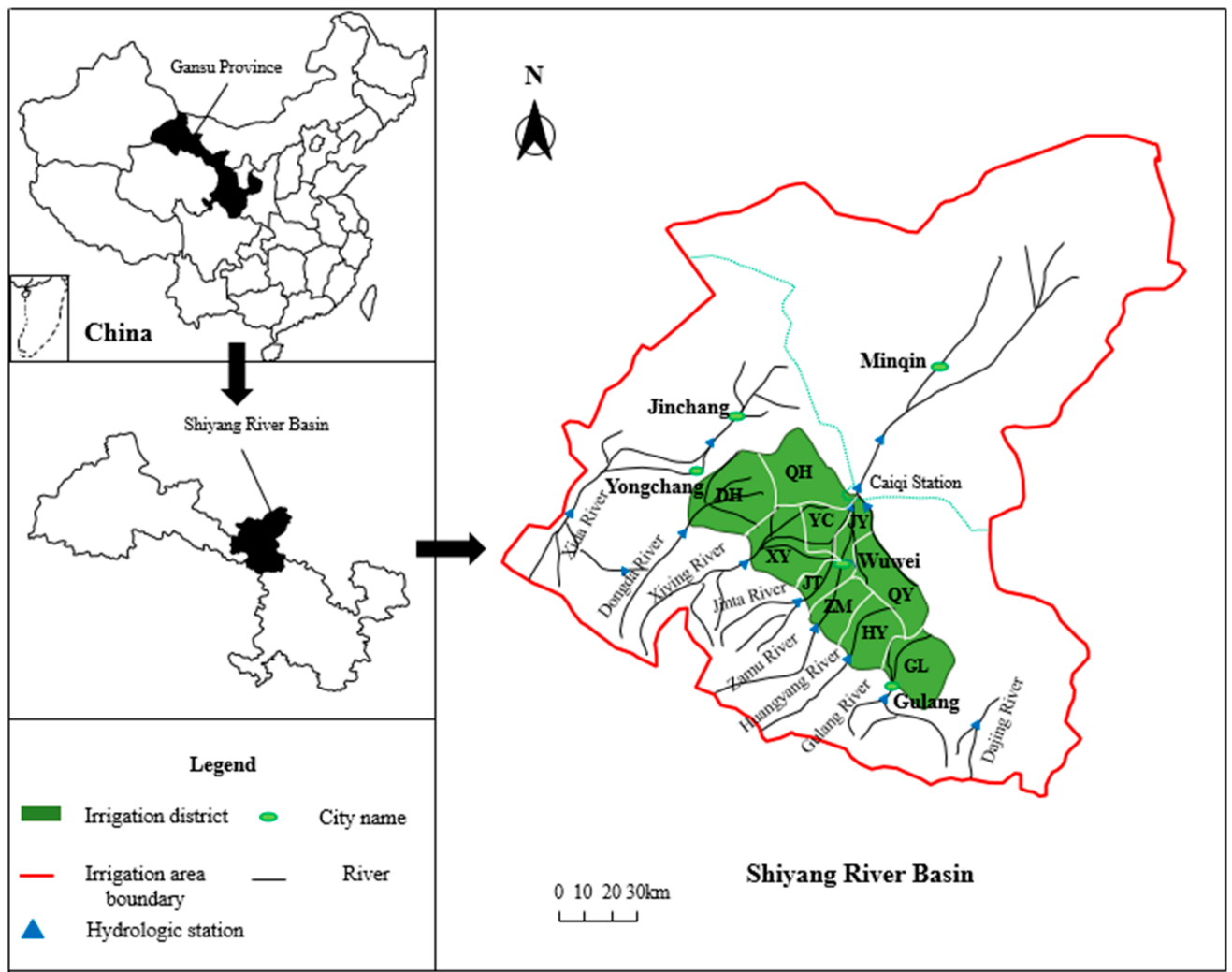

Figure 2. The study area.

\subsection{Data Collection and Processing}

The inputs of the developed model include the estimated water demands for irrigation districts, the available supplies of surface water and groundwater, the relevant crop production data, the regional meteorological data, and the economic data. In detail, the available supplies of groundwater are based on the collected data from the Shiyang River Basin Key Governance Projects [56]. The available supplies of surface water are based on historical data of the six rivers' annual runoffs from 1955 to 2009. By fitting P-III curve based on the original runoff data (Figure 3), the runoffs of six rivers can be classified as different flow levels as: Specifically, $P<12.5 \%$ corresponds to the very high flow level, $12.5 \%<P<37.5 \%$ corresponds to the high flow level, $37.5 \%<P<62.5 \%$ corresponds to the middle flow level, $62.5 \%<P<87.5 \%$ corresponds to the low flow level, and $P>87.5 \%$ corresponds to the very low flow level (where $P=\frac{m}{n+1} \times 100 \%, m$ represents the number of years with annual runoffs not less than a certain flow value, and $n$ represents the total number of years with the flow data). Therefore, the probability levels (i.e., $0.125,0.25,0.25,0.25$, and 0.125 ) and the corresponding water amounts under the five flow levels can be obtained. In this study, a confidence interval with a significance level of 0.05 is used to obtain the interval ranges of water supplies. Table 1 shows the available surface water supplies of six rivers under different flow levels. 
- Empirical distribution - P-III distribution

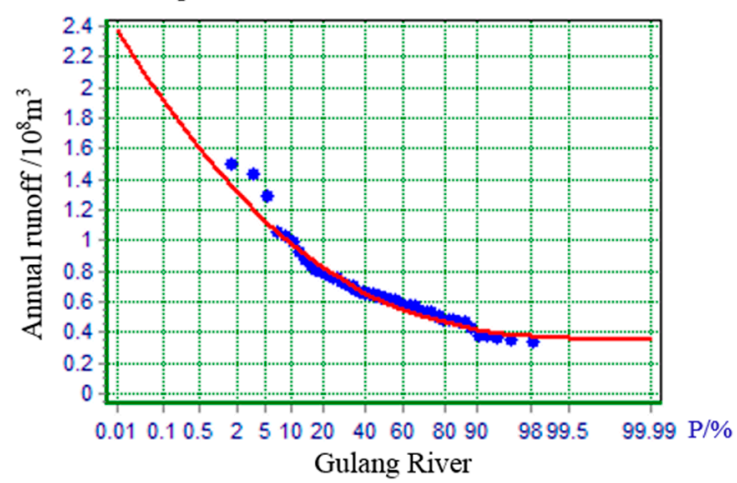

- Empirical distribution - P-III distribution

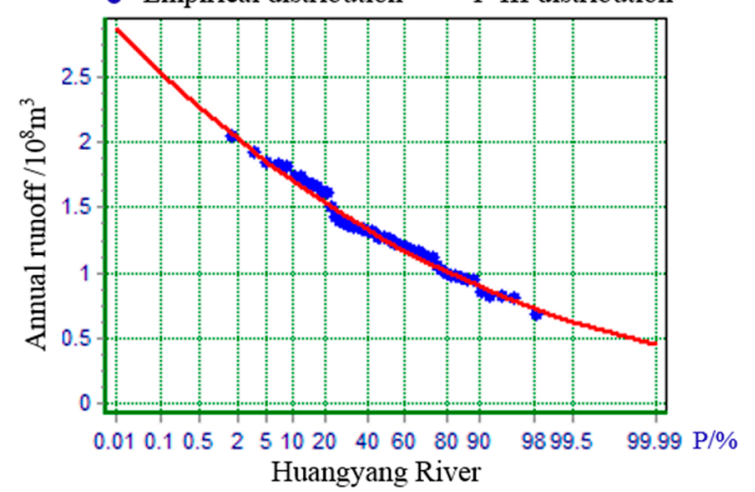

- Empirical distribution - P-III distribution
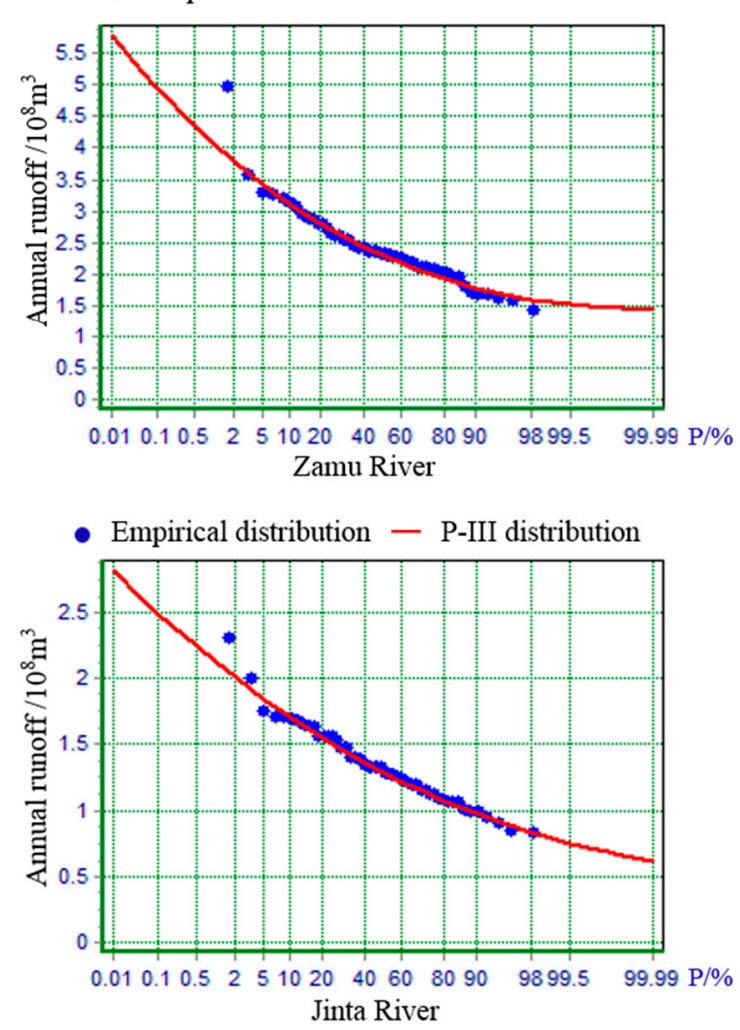

Figure 3. Cont. 


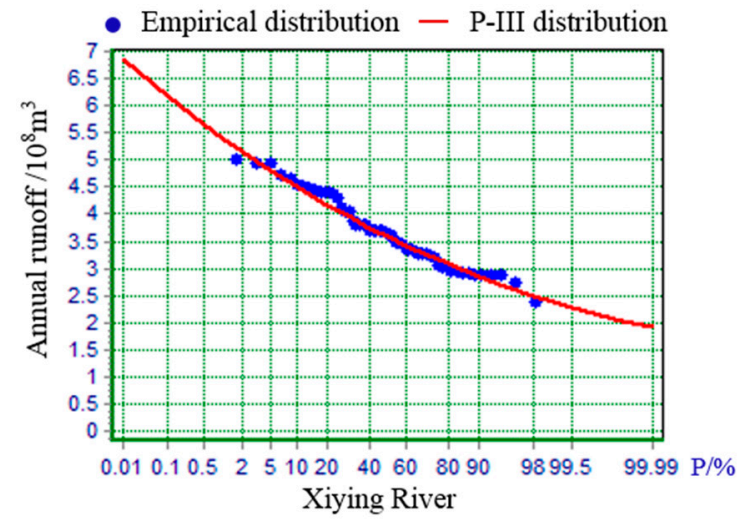

- Empirical distribution - P-III distribution

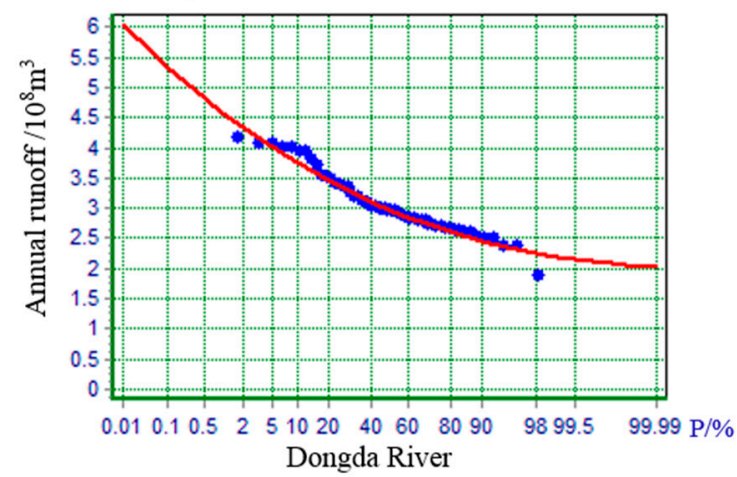

Figure 3. P-III frequency distribution curves of runoff from the six rivers.

Table 1. The runoff of the six rivers in different flow levels $\left(10^{8} \mathrm{~m}^{3}\right)$.

\begin{tabular}{ccccccc}
\hline Water Level & Gulang River & Huangyang River & Zamu River & Jingta River & Xiying River & Dongda River \\
\hline$h=1$ & {$[1.02,1.39]$} & {$[1.73,1.87]$} & {$[3.00,3.97]$} & {$[1.54,1.98]$} & {$[4.53,4.80]$} & {$[3.86,4.03]$} \\
$h=2$ & {$[0.73,0.80]$} & {$[1.39,1.54]$} & {$[2.60,2.75]$} & {$[1.49,1.57]$} & {$[4.07,4.31]$} & {$[3.29,3.43]$} \\
$h=3$ & {$[0.59,0.62]$} & {$[1.23,1.27]$} & {$[2.26,2.33]$} & {$[1.27,1.31]$} & {$[3.57,3.68]$} & {$[2.87,2.96]$} \\
$h=4$ & {$[0.47,0.52]$} & {$[0.99,1.07]$} & {$[2.00,2.07]$} & {$[1.09,1.15]$} & {$[3.10,3.24]$} & {$[2.65,2.73]$} \\
$h=5$ & {$[0.34,0.39]$} & {$[0.76,1.01]$} & {$[1.53,1.71]$} & {$[0.87,0.97]$} & {$[2.68,2.89]$} & {$[2.07,2.55]$} \\
\hline
\end{tabular}

The irrigation water demands can be obtained according to $E T_{c}=K_{c} \times E T_{0}$, where $E T_{c}$ is the actual crop evapotranspiration $\left(\mathrm{mm} /\right.$ day), $K_{c}$ is the crop coefficient, and $E T_{0}$ is the reference crop evapotranspiration (mm/day). The $E T_{0}$ value can be calculated based on the FAO 56 Penman-Monteith method [57]. The meteorological data of the Wuwei Sub-basin from 1956 to 2017 are obtained from the China Meteorological Data Sharing Service System. Annual rainfall data from 1956 to 2017 are collected from the observation stations in Wuwei and the effective rainfall coefficient is 0.8 [58]. The effective rainfall is estimated by the product of actual rainfall and the effective precipitation coefficient. The main crops in the Wuwei Basin include wheat, corn, and economic crops, and their market prices come from the 2013-2016 China Agricultural Products Price Survey Yearbook. The price of wheat is $[2.44,2.57]$ yuan $/ \mathrm{kg}$, the price of corn is $[2.09,2.47] \mathrm{yuan} / \mathrm{kg}$, and the price of economic crops is [4.94, 5.34] yuan $/ \mathrm{kg}$. Effective irrigation areas of crops are from the previous case study [55].

Table 2 shows the other parameters of the irrigation districts needed to solve the developed optimization model, such as the population data, irrigation water usage efficiencies, water productivities of different crops, areas of irrigation districts, and water prices. According to the water price adjustment policy of Wuwei City, the water price consists of two parts: The metering water price and the basic water price. For surface water supplies, the basic and metering water prices are respectively 30 yuan/ha and $0.157 \mathrm{yuan} / \mathrm{m}^{3}$; for groundwater supplies, the basic and metering water price are respectively 120 yuan/ha and 0.01 yuan $/ \mathrm{m}^{3}$. 
Table 2. The main parameters of the developed model.

\begin{tabular}{|c|c|c|c|c|c|c|c|}
\hline \multirow[b]{2}{*}{ Irrigation District } & \multirow[b]{2}{*}{ Population $\left(10^{4}\right)$} & \multirow{2}{*}{$\begin{array}{l}\text { Irrigation Water } \\
\text { Usage Efficiency }\end{array}$} & \multicolumn{2}{|c|}{ Water Productivity $/\left(\mathrm{kg} / \mathrm{m}^{3}\right)$} & \multirow{2}{*}{$\begin{array}{c}\text { Irrigation } \\
\text { Areas }\left(10^{4} \mathrm{ha}\right)\end{array}$} & \multicolumn{2}{|c|}{ Water Price } \\
\hline & & & Food Crop & Economic Crops & & $\begin{array}{c}\text { Basic Water Price } \\
\text { (yuan/ha) }\end{array}$ & $\begin{array}{l}\text { Metering Water } \\
\text { Price (yuan } / \mathrm{m}^{3} \text { ) }\end{array}$ \\
\hline Gulang & 8.77 & 0.53 & {$[1.01,1.14]$} & {$[1.61,1.81]$} & 0.58 & 30 & 0.157 \\
\hline Huangyang & 10.90 & 0.59 & {$[1.47,1.65]$} & {$[1.47,1.65]$} & 1.11 & 30 & 0.157 \\
\hline Zamu & 12.88 & 0.58 & {$[1.39,1.56]$} & {$[1.14,1.27]$} & 0.94 & 30 & 0.157 \\
\hline Jinta & 9.26 & 0.71 & {$[1.13,1.26]$} & {$[1.11,1.24]$} & 0.65 & 30 & 0.157 \\
\hline Xiying & 10.72 & 0.61 & {$[1.73,1.94]$} & {$[1.44,1.61]$} & 1.86 & 30 & 0.157 \\
\hline Donghe & 4.60 & 0.52 & {$[1.20,1.36]$} & {$[1.81,2.05]$} & 1.69 & 30 & 0.157 \\
\hline Qingyuan & 11.65 & 0.75 & {$[1.29,1.44]$} & {$[0.94,1.04]$} & 0.74 & 120 & 0.01 \\
\hline Jinyang & 10.52 & 0.72 & {$[0.97,1.08]$} & {$[0.82,0.91]$} & 0.51 & 120 & 0.01 \\
\hline Yongchang & 11.47 & 0.60 & {$[1.25,1.40]$} & {$[1.10,1.23]$} & 0.69 & 120 & 0.01 \\
\hline Qinghe & 5.14 & 0.69 & {$[0.77,0.86]$} & {$[0.98,1.09]$} & 0.83 & 120 & 0.01 \\
\hline
\end{tabular}

\section{Results Analysis and Discussion}

\subsection{The ILFBP Model Results of the Water Allocation}

Figure 4 shows the optimization allocation results of each irrigation district under different flow levels. Obviously, with the decreased incoming water, the configuration target was reduced, and the water allocation in each irrigation district was also gradually reduced.

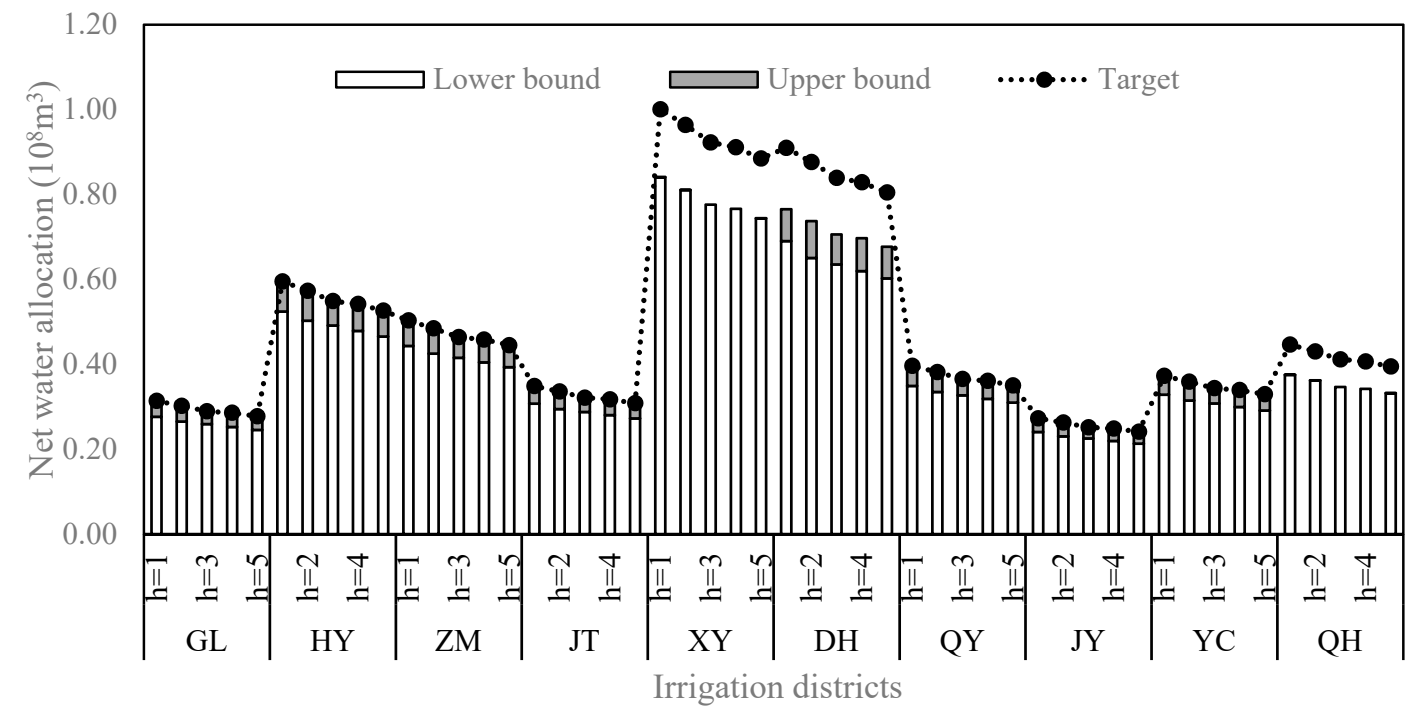

Figure 4. Water allocation at different flow levels in different irrigation districts.

Except for the irrigation districts of Xiying, Donghe, and Qinghe, the water allocation results for other irrigation districts could reach the allocation target. The Xiying irrigation district has the largest planting area, thus faces the most serious water shortage. The main water source for irrigation of the Xiying irrigation district is the Xiying River. The Xiying River is the largest tributary of the Shiyang River system, and the Xiying Reservoir is located at the exit of the mountain. The Xiying Reservoir not only provides irrigation water for the Xiying irrigation district, but also has the functions of preventing drought and flood, supplying safe drinking water for humans and animals, and transferring water to downstream. The current irrigation schemes cannot meet the water demands, resulting in serious waste of water resources and low irrigation water usage efficiency. These reasons basically answer the key question why water shortage often occurs in the Xiying irrigation district.

Figure 5 shows the water allocation results for different crops in different irrigation districts under the medium flow level. The regional water allocation for wheat, maize, and the economic crops were respectively $[5.25,5.69] \times 10^{8} \mathrm{~m}^{3},[1.23,1.34] \times 10^{8} \mathrm{~m}^{3}$, and $[0.23,0.25] \times 10^{8} \mathrm{~m}^{3}$. Aggressive decision makers may choose the upper bounds of water allocations to obtain higher food production and economic benefits, but they also need to bear relatively higher risks; conservative decision 
makers may choose the lower bounds of water allocations with relatively lower levels of benefits and risk. In general, the water allocation of food crops production is far greater than that economic crops, which has the similar trends with other previous studies in this study area [47,55]. For modern agricultural development, the water managers of irrigation districts should be able to adjust the regional planting structure and the irrigation modes in time. The water management department should guide local farmers to plant more economic crops to improve water usage efficiency. Additionally, the water supplies of economic crops should be increased to improve the agricultural economic benefits in irrigation districts.

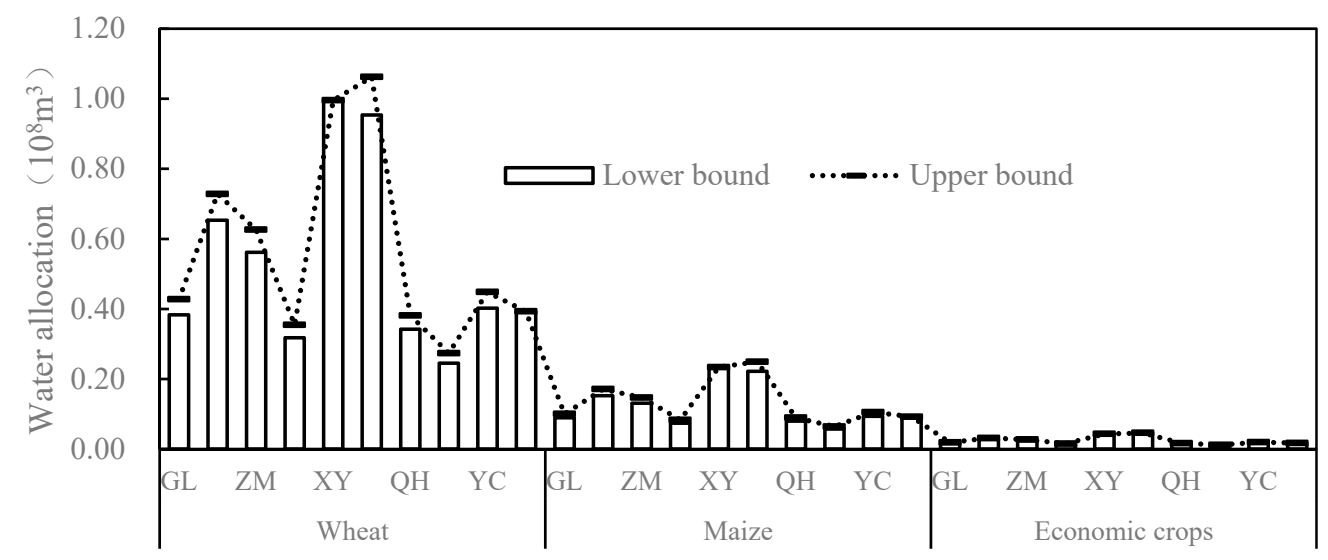

Figure 5. Water allocation for all the crops in different irrigation districts under the medium flow level.

Figure 6 shows the comparison of the total regional water allocation among the current situation, the results of the ILFBP model, and the results of the economic model without considering the system fairness. The total water allocation of the ILFBP model in the study area was $[6.73,7.37] \times 10^{8} \mathrm{~m}^{3}$, while that of the economic model is $[7.04,7.97] \times 10^{8} \mathrm{~m}^{3}$ and that of the status quo was $[7.57,8.37] \times 10^{8} \mathrm{~m}^{3}$. The total water allocation of the ILFBP model was the least one among the three schemes. Except for Xiying and Donghe irrigation districts, the water allocation of the economic model and ILFBP model was almost the same. The crop planting area and irrigation water allocation in the Xiying and Donghe irrigation districts were the largest among the study areas. However, the population of these two irrigation districts was not the largest. Therefore, in order to improve the water allocation fairness between irrigation districts, the ILFBP model appropriately reduced the water allocation of the Xiying and Donghe irrigation district.

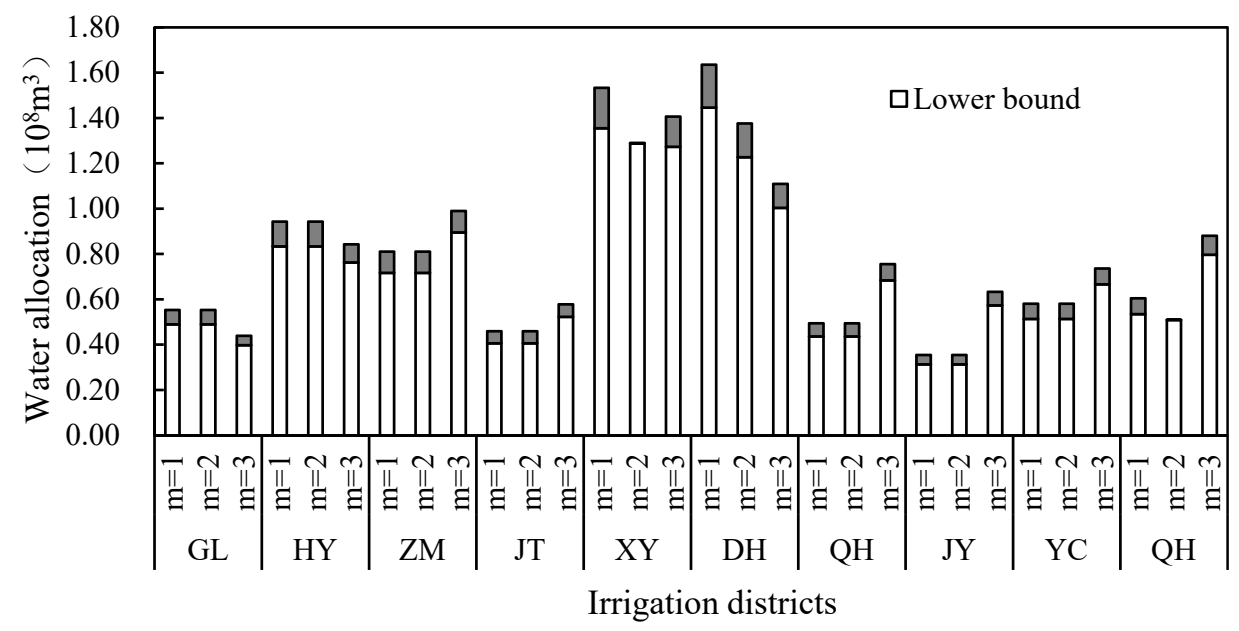

Figure 6. The total water allocation of the three water allocation schemes in each irrigation district. Note: $\mathrm{m}=1, \mathrm{~m}=2$, and $\mathrm{m}=3$ represent the economic model, ILFBP model, and status quo, respectively. 
Figure 7 shows the economic benefits of the three water allocation schemes. The economic benefits of the economic model, ILFBP model, and the status quo were respectively $[16.49,23.06] \times 10^{8}$ yuan, $[16.01,21.73] \times 10^{8}$ yuan, and $[15.66,22.04] \times 10^{8}$ yuan. The economic model only maximized the regional overall economic benefits brought by the water allocation, so more water was allocated to the irrigation areas with more economic crops to improve the overall economic benefits. Therefore, the economic model could bring higher economic benefits. The benefits of the actual situation and the ILFBP model were similar, but the interval ranges of the system benefits were different. The upper-bound benefits of the status quo were larger than those of the ILFBP model, indicating that the current situation could obtain greater benefits. However, the larger interval range of the benefits under the status quo was larger indicates greater level of uncertainties existed in the benefits of the status quo. It seems that more irrigation water could bring more economic benefits, but the marginal benefits existed in the relationship between economic benefits and water allocation amounts, which may lead to the decreased water usage efficiency when using more irrigation water. Therefore, the water allocation schemes could not be evaluated only through comparing the amount of irrigation water and economic benefits. An appropriate evaluation method is still needed to compare the effects of water allocation schemes and provide more useful decision-making information.

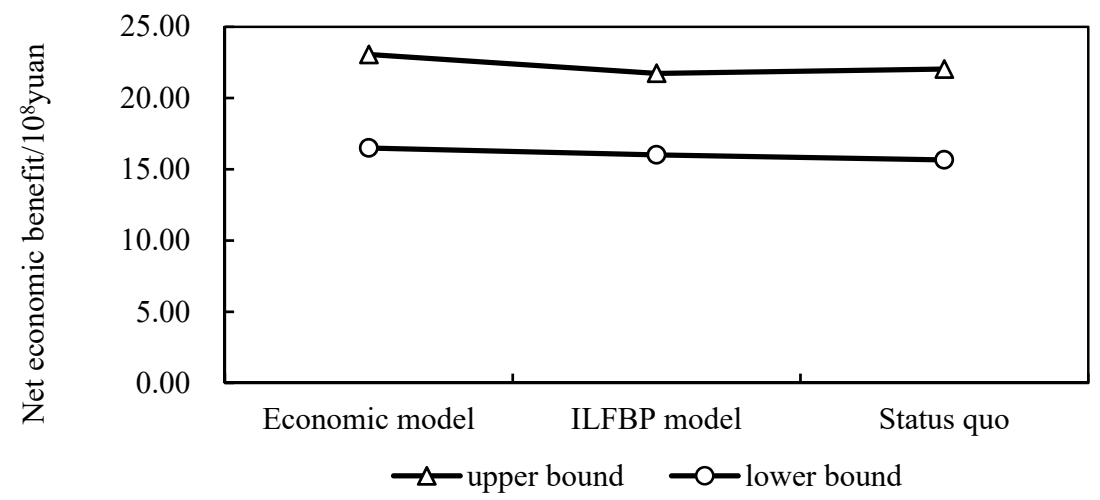

Figure 7. Economic benefits of the three water allocation schemes.

\subsection{Evaluation Results}

In order to reflect the economic, social, and resource effects of water-allocation schemes, the evaluation model indicators such as the Gini coefficient, the irrigation water productivity, the benefits per unit of water usage, the irrigation loss per unit of area, and the water shortage rate were calculated based on the results obtained from three optimization models. The values of the indicators of the three schemes are shown in Table 3.

Table 3. Decision Matrix.

\begin{tabular}{cccccc}
\hline Models & Gini Coefficient & $\begin{array}{c}\text { Irrigation Water } \\
\text { Productivity }\end{array}$ & $\begin{array}{c}\text { Benefits Per Unit of } \\
\text { Water Usage }\end{array}$ & $\begin{array}{c}\text { Irrigation Loss Per } \\
\text { Unit of Area }\end{array}$ & $\begin{array}{c}\text { Water } \\
\text { Shortage Rate }\end{array}$ \\
\hline & $/$ & $\mathrm{Kg} / \mathrm{m}^{3}$ & yuan $/ \mathrm{m}^{3}$ & $\left(10^{3} \mathrm{~m}^{3}\right) / \mathrm{ha}$ & $/$ \\
\hline Economic model & {$[0.39,0.41]$} & {$[1.27,1.44]$} & {$[2.34,2.89]$} & {$[2.90,3.27]$} & 0 \\
ILFBP model & {$[0.35,0.38]$} & {$[1.38,1.51]$} & {$[2.38,2.95]$} & {$[2.75,3.01]$} & {$[0.04,0.07]$} \\
Status quo & {$[0.29,0.31]$} & {$[1.21,1.34]$} & {$[1.87,2.63]$} & {$[2.97,3.28]$} & 0 \\
\hline
\end{tabular}

$Y_{1}, \cdots Y_{5}$ represent the above-mentioned five indicators, respectively, and the weights of the five indicators are represented by the weight vector $w$. The IAHP was used for comparing the estimation indicators to build an interval judgment matrix and calculate the results of the index weights as shown in Table 4. The calculation results of $k=0.92<1$ and $l=1.06>1$ could pass the consistency test. The weighted normalization decision matrix is shown in Table 5 . 
Table 4. Indicator judgment matrix and weight.

\begin{tabular}{ccccccc}
\hline $\boldsymbol{Y}$ & $\boldsymbol{Y}_{\mathbf{1}}$ & $\boldsymbol{Y}_{2}$ & $\boldsymbol{Y}_{3}$ & $\boldsymbol{Y}_{4}$ & $Y_{5}$ & $\boldsymbol{w}$ \\
\hline$Y_{1}$ & {$[1,1]$} & {$[2,3]$} & {$[1 / 4,1 / 2]$} & {$[4,6]$} & {$[6,7]$} & {$[0.24,0.28]$} \\
$Y_{2}$ & {$[1 / 3,1 / 2]$} & {$[1,1]$} & {$[1 / 5,1 / 4]$} & {$[2,3]$} & {$[5,6]$} & {$[0.14,0.15]$} \\
$Y_{3}$ & {$[2,4]$} & {$[4,5]$} & {$[1,1]$} & {$[5,7]$} & {$[6,8]$} & {$[0.43,0.50]$} \\
$Y_{4}$ & {$[1 / 6,1 / 4]$} & {$[1 / 3,1 / 2]$} & {$[1 / 7,1 / 5]$} & {$[1,1]$} & {$[2,3]$} & {$[0.07,0.08]$} \\
$Y_{5}$ & {$[1 / 7,1 / 6]$} & {$[1 / 6,1 / 5]$} & {$[1 / 8,1 / 6]$} & {$[1 / 3,1 / 2]$} & {$[1,1]$} & {$[0.04,0.04]$} \\
\hline
\end{tabular}

Table 5. Weighted normalized decision matrix.

\begin{tabular}{cccccc}
\hline Distance to the Ideal Solution & $Y_{1}$ & $Y_{2}$ & $Y_{3}$ & $Y_{4}$ & $Y_{5}$ \\
\hline Economic model & {$[-0.28,-0.23]$} & {$[0.12,0.15]$} & {$[0.35,0.50]$} & {$[-0.08,-0.06]$} & 0 \\
ILFBP model & {$[-0.26,-0.21]$} & {$[0.13,0.15]$} & {$[0.35,0.50]$} & {$[-0.07,-0.05]$} & {$[-0.04,-0.02]$} \\
Status quo & {$[-0.21,-0.17]$} & {$[0.11,0.13]$} & {$[0.28,0.45]$} & {$[-0.08,-0.06]$} & 0 \\
\hline
\end{tabular}

The positive ideal solution determined the ITOPSIS method is $X^{+}=$ $\{[-0.21,-0.17],[0.13,0.15],[0.35,0.50],[-0.07,-0.05],[0,0]\}$, and the negative ideal solution is $X^{-}=\{[-0.28,-0.23],[0.11,0.13],[0.28,0.45],[-0.08,-0.06],[-0.04,-0.02]\}$. The distance between each solution to the positive and negative ideal solutions is: $d_{1}^{+}=7.06 \times 10^{-2}, d_{1}^{-}=8.15 \times 10^{-2}, d_{2}^{+}=$ $6.54 \times 10^{-2}, d_{2}^{-}=7.97 \times 10^{-2}, d_{3}^{+}=7.69 \times 10^{-2}, d_{3}^{-}=8.06 \times 10^{-2}$. The relative closeness of each scheme is $C_{1}=5.36 \times 10^{-1}, C_{2}=5.49 \times 10^{-1}, C_{3}=5.12 \times 10^{-1}$. From the above results, the ranking result of the three schemes can be obtained as $C_{2}>C_{1}>C_{3}$.

The evaluation results show that the applicability of the ILFBP model is better than other two models in this study area. The regional economic, resource, and social indicators can be improved by adjusting the water allocation schemes for different irrigation districts. Among the three schemes, the state quo showed the highest level of fairness among the three schemes with the Gini coefficient of only $[0.29,0.31]$, but the regional economic growth and local irrigation water productivity were also limited by strong fairness concerns. In the economic model, in order to obtain greater economic benefits, more water was distributed to the irrigation districts with more economic crops, such as Xiying, Donghe, and Qinghe. However, this leads to unfair water distribution between irrigation districts. The Gini coefficient of the economic model was $[0.39,0.41]$, which was close to triggering the warning sign. The ILFBP model coordinates the decision-making preferences of two-level stakeholders with the considerations of system economic benefits and system fairness. These efforts contribute to the social contradiction caused by the extremely unfair water allocation among irrigation districts. The Gini coefficient of the ILFBP scheme was lower than 0.4 . The superiority of the ILFBP model could also be reflected through the indicator comparison, such as irrigation loss, irrigation water productivity, and benefit per unit water. These results indicate that the water allocation scheme obtained by ILFBP could effectively reduce unnecessary water waste and make most of the indicators closer to the positive ideal solution.

\subsection{Discussion}

This study used the ILFBP model as a planning management tool to improve irrigation-water use efficiency and further increase available ecological water in the Shiyang River Basin. The results obtained from ILFBP model provided specific adjustment and allocation recommendations under different flow levels, which contributed to the sustainable development of local agriculture.

The effects evaluation of the water allocation schemes could test the applicability of the ILFBP model to the specific regions, and further improve the implementation significance of the optimization schemes for practical problems. The IAHP-TOPSIS evaluation method could deal with uncertainties and provide more practical strategies than existing deterministic evaluation models. The uncertainties associated with the water allocation variables and the subjective preferences could be fully reflected in the expert evaluation process. 
In order to evaluate the effects of the ILFBP model comprehensively, two models, respectively the status quo situation and the single economic goal without the fairness concern, were built and solved. The obtained results showed that the ILFBP model could coordinate the economic benefits and fairness of system under uncertainty. Moreover, it could improve the water allocation effects from multiple perspectives, and obtained an irrigation-water allocation scheme with a high satisfaction degree for different stakeholders. The water allocation schemes obtained from the ILFBP model were obviously more reasonable than the status quo, and could meet the policy making requirements of the Shiyang River Basin. These efforts could help local water managers of the Shiyang River Basin formulate more suitable water policies.

Compared with other previous studies on water resources allocation in the Shiyang River Basin $[29,47,51]$, the ILFBP model could obtain a satisfied irrigation-water allocation scheme by considering the system fairness and making tradeoff between the upper- and lower-level decision makers under uncertainty. Moreover, the optimization-evaluation framework developed in this study could not only provide specific water allocation schemes, but also evaluate the effectiveness and the applicability of the optimization schemes, making the results more convincing and more realistic.

Furthermore, the optimization-evaluation framework developed in this study could be applied to other regions for improving water resource management at a government, regional, local, and basin level. The specific planning benefits and the evaluation results are associated with irrigation water allocation, ecological water allocation, different flow levels, and interval range of social and economic parameters. These data can be obtained through field research or model programming. Therefore, the proposed optimization-evaluation framework under uncertainty is universal and has significant implications for supporting regional water allocation practices, especially in arid and semi-arid regions.

\section{Conclusions}

In this study, an interval linear fractional bi-level programming (ILFBP) model was developed for irrigation-water allocation planning under uncertainty. The bi-level planning (BP), interval planning (IP) and linear fractional programming (LFP) techniques are integrated to deal with the problems in reality. The interactive fuzzy coordination algorithm was used for solving the developed model, and the interval solutions under different flow levels could be obtained. In order to reasonably evaluate the effects of the optimization schemes under uncertainty, the interval analytic hierarchy process (IAHP) method and the interval TOPSIS method were simultaneously applied for evaluating the obtained allocation schemes. The developed optimization-evaluation approach was applied to a real-world case study in the middle reaches of the Shiyang River Basin. Compared with the previous studies, the developed framework had the following advantages. (1) It could consider the decision-making preferences of multi-level stakeholders and reflect different priorities existed in the decision-making process. The goals of the upper-level decision makers could be prioritized, and then be weighed among the two levels of decision makers, and finally the decision-making plan with higher overall satisfaction could be obtained; (2) the fairness goal could be added to the water resources optimization model to ensure system fairness of allocation schemes under uncertainty; (3) it could quantify the subjective intention of the experts and reflect the uncertainty in this process; and (4) it could provide the corresponding effects evaluation for optimization schemes under interval uncertainty. The proposed approach could help decision makers develop and identify more appropriate water-irrigation schemes. This framework could also be applied to other practical problems of resources and environmental management for developing well-rounded strategies under various system complexities.

Author Contributions: Conceptualization, F.Z.; Data curation, Y.Z.; Formal analysis, Y.Z., F.Z. and H.Z.; Methodology, Y.Z.; Project administration, P.G.; Resources, P.G.; Software, Y.Z.; Validation, F.Z. and P.G.; Writing-review \& editing, Y.Z., F.Z., H.Z. and P.G.

Funding: This research was funded by the National Natural Science Foundation of China grant number [41871199, 51621061]. 
Acknowledgments: The authors are grateful to the editor and the anonymous reviewers for their insightful comments and suggestions.

Conflicts of Interest: The authors declare no conflict of interest.

\section{Abbreviations}

$\begin{array}{ll}\text { Abbreviation } & \text { Meaning and Description } \\ \text { ILFBP } & \text { Interval linear fractional bi-level programming } \\ \text { IAHP } & \text { Interval analytic hierarchy process } \\ \text { ITOPSIS } & \text { Interval-parameter TOPSIS method } \\ \text { MCDM } & \text { Multi-criteria decision making } \\ \text { ULDM } & \text { Upper-level decision maker } \\ \text { LLDM } & \text { Lower-level decision maker } \\ \text { FP } & \text { Fuzzy programming } \\ \text { SP } & \text { Stochastic programming } \\ \text { IP } & \text { Interval programming } \\ \text { BP } & \text { Bi-level programming } \\ \text { ILP } & \text { Interval linear programming } \\ \text { ILFP } & \text { Interval linear fractional programming } \\ \text { ILBP } & \text { Interval linear bi-level programming } \\ \text { GL } & \text { Gulang irrigation district } \\ \text { HY } & \text { Huangyang irrigation district } \\ \text { ZM } & \text { Zamu irrigation district } \\ \text { JT } & \text { Jinta irrigation district } \\ \text { XY } & \text { Xiying irrigation district } \\ \text { DH } & \text { Donghe irrigation district } \\ \text { QY } & \text { Qingyuan irrigation district } \\ \text { JY } & \text { Jingyang irrigation district } \\ \text { YC } & \text { Yongchang irrigation district } \\ \text { QH } & \text { Qinghe irrigation district } \\ \end{array}$

\section{Parameters}

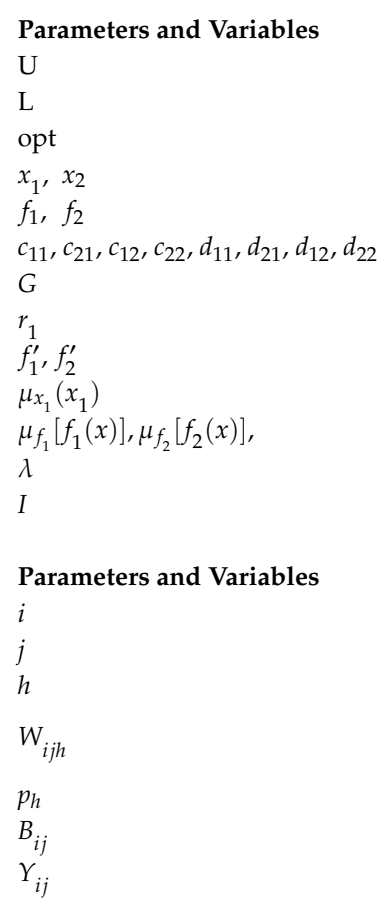

\section{The ILFBP Methods}

Meaning and Description

Upper-level

Lower-level

The optimal values

The upper- and lower-level decision variables

The upper- and lower-level objective functions

Interval parameters

The set of bi-level constraints

The maximum tolerances of the upper-level decision variables

The worst values of the upper- and lower-level objective functions

The satisfaction degrees of the upper-level decision variables

The satisfaction degrees of the upper- and lower-level objective functions

The overall satisfactory degree of the ILFBP model

A column vector with the same dimension as $x$ and all elements of $I$ equal to 1

The application of the ILFBP model

Meaning and Description

Irrigation districts

Crop types

Flow levels

The amount of irrigation water allocated to the crop $j$ in the irrigation district $i$ under the flow level $h\left(\mathrm{~m}^{3}\right)$, the decision variables

The possibilities of different flow levels

The prices of crop $j$ in the irrigation district $i$ (yuan $/ \mathrm{kg}$ )

The water productivities of crop $j$ in the irrigation district $i\left(\mathrm{~kg} / \mathrm{m}^{3}\right)$ 




\section{Parameters and Variables}

$X_{m}$

$Y_{n}$

$A^{ \pm}=\left(a_{m n}^{ \pm}\right)_{M \times N}$

$R^{ \pm}=\left(r_{m n}^{ \pm}\right)_{M \times N}$

$\left\|A_{n}\right\|$

$B^{ \pm}=\left(b_{m n}^{ \pm}\right)_{N \times N}$

$w_{n}^{ \pm}$

$x_{n}^{ \pm}$

$k, l$

$S^{ \pm}=\left(s_{m n}^{ \pm}\right)_{M \times N}$

$d_{m}^{+}, d_{m}^{-}$

$X^{+}, X^{-}$

$\mathrm{C}_{m}$
The application of the ILFBP model

Meaning and Description

Irrigated areas of subarea $i$ (ha)

The irrigation water use efficiency

Effective precipitation $\left(\mathrm{m}^{3}\right)$

Basic water price (yuan/ha)

The metering water price $\left(\mathrm{yuan} / \mathrm{m}^{3}\right.$ )

Populations of the irrigation district $i$

The total water supplies under the flow level $h\left(\mathrm{~m}^{3}\right)$

Water supplies for the irrigation district $i$ under flow level $h\left(\mathrm{~m}^{3}\right)$

The minimum and maximum crop water requirement of crop $j$ in the irrigation district $i$

under flow level $h\left(\mathrm{~m}^{3}\right)$

The IAHP-TOPSIS evaluation methods

Meaning and Description

Alternatives $(m=1,2, \cdots, M)$

Indicators $(n=1,2, \cdots, N)$

Interval-number decision matrix

Standardized interval-number decision matrix

The norm of the $j$ th column vector

Interval judgment matrix

The interval weights

Eigenvectors

Parameters required to calculate interval weights

Weighted normalized decision matrix

The distance from the scheme alternative $X_{m}$ to the positive and the Negative ideal

solution, respectively

The positive ideal and negative ideal solutions

The relative closeness

\section{References}

1. Xu, Q.; Chen, Q.; Zhao, S.; Liu, K.; Ma, J. Saving Water and Associated Energy from Distribution Networks by Considering Landscape Factors in Pressure Management and Use of District Metered Areas. J. Environ. Inform. 2017, 31, 65-73. [CrossRef]

2. Tan, Q.; Zhang, S.; Li, R. Optimal use of agricultural water and land resources through reconfiguring crop planting structure under socioeconomic and ecological objectives. Water 2017, 9, 488. [CrossRef]

3. Kang, S.; Hao, X.; Du, T.; Tong, L.; Su, X.; Lu, H.; Li, X.; Huo, Z.; Li, S.; Ding, R. Improving agricultural water productivity to ensure food security in China under changing environment: From research to practice. Agric. Water Manag. 2017, 179, 5-17. [CrossRef]

4. Hrozencik, R.A.; Manning, D.T.; Suter, J.F.; Goemans, C.; Bailey, R.T. The heterogeneous impacts of groundwater management policies in the Republican River Basin of Colorado. Water Resour. Res. 2017, 53, 10757-10778. [CrossRef]

5. Al-Isawi, R.H.; Scholz, M.; Al-Faraj, F.A. Assessment of diesel-contaminated domestic wastewater treated by constructed wetlands for irrigation of chillies grown in a greenhouse. Environ. Sci. Pollut. Res. 2016, 23, 25003-25023. [CrossRef]

6. Al-Isawi, R.H.K.; Almuktar, S.A.A.-A.N.; Scholz, M. Recycling of river, rain, gully pot and grey waters for irrigating chillies. Environ. Monit. Assess. 2016, 188, 1-12. [CrossRef] [PubMed]

7. Sethi, L.N.; Kumar, D.N.; Panda, S.N. Optimal crop planning and conjunctive use of water resources in a coastal river basin. Water Resour. Manag. 2002, 16, 145-169. [CrossRef]

8. Guo, P.; Huang, G.H.; He, L.; Sun, B.W. ITSSIP: Interval-parameter two-stage stochastic semi-infinite programming for environmental management under uncertainty. Environ. Model. Softw. 2008, 23, 1422-1437. [CrossRef]

9. Li, M.; Guo, P.; Fang, S.Q.; Zhang, L.D. An inexact fuzzy parameter two-stage stochastic programming model for irrigation water allocation under uncertainty. Stoch. Environ. Res. Risk Assess. 2013, 27, 1441-1452. [CrossRef]

10. Li, Y.P.; Huang, G.H.; Guo, P.; Yang, Z.F.; Nie, S.L. A dual-interval vertex analysis method and its application to environmental decision making under uncertainty. Eur. J. Oper. Res. 2010, 200, 536-550. [CrossRef] 
11. Huang, G.H. A hybrid inexact-stochastic water management model. Eur. J. Oper. Res. 1998, 107, $137-158$. [CrossRef]

12. Zhang, C.; Li, M.; Guo, P. An interval multistage joint-probabilistic chance-constrained programming model with left-hand-side randomness for crop area planning under uncertainty. J. Clean. Prod. 2017, 167, 1276-1289. [CrossRef]

13. Zhang, D.; Guo, P. Integrated agriculture water management optimization model for water saving potential analysis. Agric. Water Manag. 2016, 170, 5-19. [CrossRef]

14. Madani, K. Game theory and water resources. J. Hydrol. 2010, 381, 225-238. [CrossRef]

15. Camacho-Vallejo, J.F.; Gonzalez-Rodriguez, E.; JavierAlmaguer, F.; Gonzaez-Ramirez, R.G. A bi-level optimization model for aid distribution after the occurrence of a disaster. J. Clean. Prod. 2015, 105, 134-145. [CrossRef]

16. Lv, Y.; Huang, G.; Li, Y.; Yang, Z. Planning regional water resources system using an interval fuzzy bi-level programming method. J. Environ. Inform. 2010, 16, 43-56. [CrossRef]

17. Chen, Y.; Hongwei, L.U.; Jing, L.I.; Lixia, R.E.N.; Li, H.E. Empirical research on bi-level allocation model of water resources under uncertainty (in Chinese). Acta Sci. Circumstantiae 2016, 36, 2252-2261.

18. Hu, Z.; Wei, C.; Yao, L.; Li, L.; Li, C. A multi-objective optimization model with conditional value-at-risk constraints for water allocation equality. J. Hydrol. 2016, 542, 330-342. [CrossRef]

19. Zhang, C.; Engel, B.A.; Guo, P.; Zhang, F.; Guo, S.; Liu, X.; Wang, Y. An inexact robust two-stage mixed-integer linear programming approach for crop area planning under uncertainty. J. Clean. Prod. 2018, 204, 489-500. [CrossRef]

20. Feng, T.; Yang, Z. A New Algorithm for Weighted Proportional Fairness Based Spectrum Allocation of Cognitive Radios. In Proceedings of the 8th Acis International Conference on Software Engineering, Melbourne, Australia, 11-13 July 2007.

21. Uchida, M.; Kurose, J. An Information-Theoretic Characterization of Weighted alpha-Proportional Fairness. In Proceedings of the IEEE INFOCOM, Rio de Janeiro, Brazil, 19-25 April 2009.

22. Alvaredo, F. A note on the relationship between top income shares and the Gini coefficient. Econ. Lett. 2011, 110, 274-277. [CrossRef]

23. Karagiannis, E.; Kovacevic, M. A Method to Calculate the Jackknife Variance Estimator for the Gini Coefficient. Oxf. Bull. Econ. Stat. 2010, 62, 119-122. [CrossRef]

24. Zhang, Y.B.; Mai, Z.Q.; Chen, X.G. Analysis of city resource-environment Gini coefficient in Guangdong Province. Acta Ecol. Sin. 2008, 49, 29-38.

25. Chotikapanich, D. A comparison of alternative functional forms for the Lorenz curve. Econ. Lett. 1993, 41, 129-138. [CrossRef]

26. Qi, L. Gini-coefficient of Chinese manufacturing industry. Stat. Res. 2003, 9, 21-25.

27. Gregorio, J.D.; Lee, J.W. Education and income inequality: New evidence from cross-country data. Rev. Income Wealth 2002, 48, 395-416. [CrossRef]

28. Zhang, C.; Huan, Z.; Li, H. An Empirical Study on Education Equality Based on Education Gini Coefficient in China: 1978-2004. Tsinghua J. Educ. 2006, 27, 10-14. (In Chinese)

29. Ren, C.; Guo, P.; Tian, Q.; Zhang, L. A multi-objective fuzzy programming model for optimal use of irrigation water and land resources under uncertainty in Gansu Province, China. J. Clean. Prod. 2017, 164, 85-94. [CrossRef]

30. Zhang, C.; Li, M.; Guo, P. Two-stage stochastic chance-constrained fractional programming model for optimal agricultural cultivation scale in an arid area. J. Irrig. Drain. Eng. 2017, 143, 05017006. [CrossRef]

31. Zhang, F.; Guo, S.; Ren, C.; Guo, P. Integrated IMO-TSP and AHP Method for Regional Water Allocation under Uncertainty. J. Water Resour. Plan. Manag. 2018, 144, 04018025. [CrossRef]

32. Zhang, Y.; Guo, P.; Zhang, F.; Tang, Y. Applicability comparison of water resources optimization model based on effect evaluation. J. Drain. Irrig. Mach. Eng. 2019, 37, 154-159. (In Chinese)

33. Zhang, S.; Sun, B.; Yan, L.; Wang, C. Risk identification on hydropower project using the IAHP and extension of TOPSIS methods under interval-valued fuzzy environment. Nat. Hazards 2013, 65, 359-373. [CrossRef]

34. Sugihara, K.; Tanaka, H. Interval evaluations in the analytic hierarchy process by possibility analysis. Comput. Intell. 2001, 17, 567-579. [CrossRef]

35. Zhang, C.; Su, X.; Cai, H. Harmony Evaluation of Water Resources Allocation System in Yuyang Area Based on IAHP. J. Nat. Resour. 2017, 32, 105-1063. (In Chinese) 
36. Xu, Z.; Da, Q. A Possibility-based Method for Priorities of Interval Judgement Matrices. Chin. J. Manag. Sci. 2003, 11, 63-65.

37. Zhang, Q.; Fan, Z.; Pan, D. A Ranking Approach for Interval Numbers in Uncertain Multiple Attribute Decision Making Problems. Syst. Eng. Theory Pract. 1999, 19, 129-133. (In Chinese)

38. Jahanshahloo, G.R.; Lotfi, F.H.; Izadikhah, M. An algorithmic method to extend TOPSIS for decision-making problems with interval data. Appl. Math. Comput. 2006, 175, 1375-1384. [CrossRef]

39. Dymova, L.; Sevastjanov, P.; Tikhonenko, A. A direct interval extension of TOPSIS method. Expert Syst. Appl. 2013, 40, 4841-4847. [CrossRef]

40. Tsaur, R. Decision risk analysis for an interval TOPSIS method. Appl. Math. Comput. 2011, 218, 4295-4304. [CrossRef]

41. Jin, S.W.; Li, Y.P.; Nie, S. An integrated bi-level optimization model for air quality management of Beijing's energy system under uncertainty. J. Hazard. Mater. 2018, 350, 27-37. [CrossRef]

42. Ahlatcioglu, M.; Tiryaki, F. Interactive fuzzy programming for decentralized two-level linear fractional programming (DTLLFP) problems. Omega 2007, 35, 432-450. [CrossRef]

43. Emam, O.E. A fuzzy approach for bi-level integer non-linear programming problem. Appl. Math. Comput. 2006, 172, 62-71. [CrossRef]

44. Zhu, H.; Huang, W.W.; Huang, G.H. Planning of regional energy systems: An inexact mixed-integer fractional programming model. Appl. Energy 2014, 113, 500-514. [CrossRef]

45. Guo, P.; Huang, G.H.; He, L.; Li, H.L. Interval-parameter Fuzzy-stochastic Semi-infinite Mixed-integer Linear Programming for Waste Management under Uncertainty. Environ. Model. Assess. 2009, 14, 521-537. [CrossRef]

46. Zhang, F.; Tan, Q.; Zhang, C.; Guo, S.; Guo, P. A Regional Water Optimal Allocation Model Based on the Cobb-Douglas Production Function under Multiple Uncertainties. Water 2017, 9, 923. [CrossRef]

47. Wang, H.; Zhang, C.; Guo, P. An Interval Quadratic Fuzzy Dependent-Chance Programming Model for Optimal Irrigation Water Allocation under Uncertainty. Water 2018, 10, 684. [CrossRef]

48. Xiao, J.; Wang, C.; Zhou, M. An IAHP-based MADM method in urban power system planning. Proc. CSEE 2004, 4, 50-57. (In Chinese)

49. Zhang, J.; Liu, J. The Study of Decision Making Method to Interval Number Multiple Attribute Decision Making Problem. Forecasting 2002, 21, 73-75. (In Chinese)

50. Wei, Y.; Liu, J.; Wang, X. Concept of consistence and weights of the judgement matrix in uncertain type of AHP. Syst. Eng. Theory Pract. 1994, 14, 16-22.

51. Zhang, F.; Li, M.; Guo, S.; Zhang, C.; Guo, P. Integrated uncertain models for runoff forecasting and crop planting structure optimization of the Shiyang River Basin, north-west China. Front. Agric. Sci. Eng. 2018, 5, 177-187. [CrossRef]

52. Wang, Q.; Shi, J.; Chen, G.; Xue, L. Environmental effects induced by human activities in arid Shiyang River basin, Gansu province, northwest China. Environ. Geol. 2002, 43, 219-227.

53. Shi, Q.; Chen, F.H.; Zhu, Y.; Madsen, D. Lake evolution of the terminal area of Shiyang River drainage in arid China since the last glaciation. Quat. Int. 2002, 93, 31-43. [CrossRef]

54. Chen, M. Thoughts concerning the Shiyanghe River Basin improvement. China Water Resour. 2010, 1, 36-38. (In Chinese)

55. Zhang, L.; Guo, P.; Fang, S.; Li, M. Monthly Optimal Reservoirs Operation for Multicrop Deficit Irrigation under Fuzzy Stochastic Uncertainties. J. Appl. Math. 2014, 1-11. [CrossRef]

56. Gansu Provincial Department of Water Resources. Shiyang River Basin Key Governance Projects; Gansu Provincial Department of Water Resources: Gansu, China, 2007. (In Chinese)

57. Allen, R.G.; Pereira, L.S.; Raes, D.; Smith, M. Crop Evapotranspiration-Guidelines for Computing Crop Water Requirements-FAO Irrigation and Drainage Paper 56; FAO: Rome, Italy, 1998; Volume 156, p. 178.

58. Xu, X.; Zhou, H.; Wang, Z.; Jiapaer, R. Study on effective rainfall use efficiency in arid irrigation district. Water Sav. Irrig. 2010, 12, 44-46.

(C) 2019 by the authors. Licensee MDPI, Basel, Switzerland. This article is an open access article distributed under the terms and conditions of the Creative Commons Attribution (CC BY) license (http://creativecommons.org/licenses/by/4.0/). 